\title{
Laminarin from Irish Brown Seaweeds Ascophyllum nodosum and Laminaria hyperborea: Ultrasound Assisted Extraction, Characterization and Bioactivity
}

\author{
Shekhar U. Kadam ', Colm P. O'Donnell ${ }^{1}$, Dilip K. Rai ${ }^{2}$, Mohammad B. Hossain ${ }^{2}$, \\ Catherine M. Burgess ${ }^{3}$, Des Walsh ${ }^{3}$ and Brijesh K. Tiwari ${ }^{2, *}$
}

1 School of Biosystems and Food Engineering, University College Dublin, Belfield, Dublin 4, Ireland; E-Mails: shekhar.kadam@ucdconnect.ie (S.U.K.); colm.odonnell@ucd.ie (C.P.O.)

2 Food Biosciences, Teagasc Food Research Centre, Dublin 15, Ireland; E-Mails: dilip.rai@teagasc.ie (D.K.R.); mohammad.hossain@teagasc.ie (M.B.H.)

3 Food Safety, Teagasc Food Research Centre, Dublin 15, Ireland; E-Mails: Kaye.Burgess@teagasc.ie (C.M.B.); des.walsh@teagasc.ie (D.W.)

* Author to whom correspondence should be addressed; E-Mail: brijesh.tiwari@teagasc.ie; Tel.: +353-1-805-9785.

Academic Editor: Paola Laurienzo

Received: 14 April 2015 / Accepted: 1 July 2015 / Published: 10 July 2015

\begin{abstract}
Ultrasound assisted extraction (UAE), purification, characterization and antioxidant activity of laminarin from Irish brown seaweeds Ascophyllum nodosum and Laminarina hyperborea were investigated. UAE was carried out using $60 \%$ ultrasonic power amplitude and $0.1 \mathrm{M}$ hydrochloric acid for $15 \mathrm{~min}$. Separately, solid-liquid extraction was carried in an orbital shaker using $0.1 \mathrm{M}$ hydrochloric acid at $70{ }^{\circ} \mathrm{C}$ for $2.5 \mathrm{~h}$. UAE with hydrochloric acid resulted in the highest concentration of laminarin, $5.82 \%$ and $6.24 \%$ on dry weight basis from A. nodosum and L. hyperborea, respectively. Purification of all extracts was carried out using molecular weight cut off dialysis at $10 \mathrm{kDa}$. Characterization of the laminarin fraction was carried out using matrix assisted laser desorption/ionization time-of-flight mass spectrometry. Antioxidant activity of A. nodosum and L. hyperborea extracts had 2,2-diphenyl-1-picrylhydrazyl (DPPH) inhibition levels of $93.23 \%$ and $87.57 \%$, respectively. Moreover, these extracts have shown inihibition of bacterial growth of Staphylcoccus aureus, Listeria monocytogenes, Escherichia coli and Salmonella typhimurium.
\end{abstract}


Keywords: laminarin; antioxidant; antimicrobial; bioactive; Laminaria hyperborea; Ascophyllum nodosum

\section{Introduction}

Half of all global biodiversity is present in the marine ecosystem. Marine organisms are an excellent source of bioactive compounds. Marine algae, one of the important components of the marine ecosystem, are a good source of carotenoids, vitamins, minerals, phenolic compounds, sulphated polysaccharides, peptides and proteins [1]. These compounds have been demonstrated to possess diverse biological activities including anti-tumor, anti-viral, anti-coagulant, anti-allergic, anti-viral, anti-tumor and antibacterial [2]. Extracts from these seaweeds have been investigated for use as ingredients in food and feed products [3]. Ascophyllum nodosum is a brown seaweed which belongs to the Phaeophyceae class and it is the only species in the genus Ascophyllum. It is good source of fucoidan, alginates, ascophyllan, laminarins and polyphenols [4]. Laminaria hyperborea is a large, leathery brown seaweed from the Laminariaceae species which is found on the coast of Norway, Scotland and Ireland. It is commercially exploited by the hydrocolloid industry for alginate production [5]. Crude extracts from this seaweed are rich in phenolic compounds and $\beta$-glucan polysaccharides known as laminarins.

Laminarins are composed of (1,3)- $\beta$-D-glucan [6]. They consist of $(1,3)-\beta$-D-glucopyranose residues with some 6-O-branching in the main chain and some $\beta-(1,6)$-intrachain links are also present. The molecular weight of laminarin is approximately $5 \mathrm{kDa}$ [7]. Both water soluble and insoluble forms of laminarin exist depending mainly on the level of branching [8]. In general, extraction of laminarin involves grinding, precipitation in an mild acid medium, ultrafiltration and dialysis [9]. Characterization of laminarin rich extracts can be carried out by high performance size exclusion chromatography using a refractive index detector [10], matrix assisted laser desorption/ionization time-of-flight (MALDI-TOF) with dehydroxy-benzoic acid as matrix [11] and nuclear magnetic resonance spectroscopy using the ${ }^{1} \mathrm{H}-{ }^{13} \mathrm{C}$ heteronuclear single quantum coherence method [12].

However, current methods of extraction of laminarin are time and energy intensive, and result in poor yields. The development of novel eco-friendly extraction techniques is required to improve extraction rate and yield. Ultrasound is a low cost, easy to use, environment friendly technology suitable for the extraction of bioactive compounds from natural sources [13]. There are no reported studies on the use of ultrasound assisted extraction for laminarin applications. Only a limited number of studies on the characterization of laminarin-rich extract from brown seaweeds are available in the literature $[6,11,12]$. This study investigates the efficiency of ultrasound assisted extraction of laminarin in comparison to traditional extraction methods, and characterizes the resultant laminarin rich extracts with respect to molecular weight, chemical properties in addition to antioxidant and antimicrobial activities. 


\section{Results and Discussion}

\subsection{Laminarin and Phenolics Content}

In this study two seaweed species harvested from the west coast of Ireland were selected for the extraction of laminarin. Laminarin was extracted using ultrasound assisted extraction and conventional solid liquid extraction using water and $0.1 \mathrm{M} \mathrm{HCl}$ (Table 1).

Table 1. Laminarin and total phenolic content of different extracts.

\begin{tabular}{lclcccc}
\hline Seaweed Species & $\begin{array}{c}\text { Solvent } \\
\text { Type }\end{array}$ & $\begin{array}{c}\text { Extraction } \\
\text { Method }\end{array}$ & $\begin{array}{c}\text { Time } \\
\text { (min) }\end{array}$ & $\begin{array}{c}\text { Sample } \\
\text { Code }\end{array}$ & $\begin{array}{c}\text { Laminarin } \\
\text { Assay (\% db) }\end{array}$ & $\begin{array}{c}\text { Total Phenolic } \\
\text { Content } \\
\text { (mg PGE/gdb }\end{array}$ \\
\hline Laminaria hyperborea & Water & Ultrasound & 15 & LHWU & $5.975 \pm 0.467$ & $0.365 \pm 0.039$ \\
Laminaria hyperborea & $0.1 \mathrm{M} \mathrm{HCl}$ & Ultrasound & 15 & LHAU & $6.240 \pm 0.008$ & $0.343 \pm 0.003$ \\
Laminaria hyperborea & Water & Solid liquid & 150 & LHWS & $4.362 \pm 0.197$ & $0.363 \pm 0.057$ \\
Laminaria hyperborea & $0.1 \mathrm{M} \mathrm{HCl}$ & Solid liquid & 150 & LHAS & $3.254 \pm 0.235$ & $0.352 \pm 0.021$ \\
Ascophyllum nodosum & Water & Ultrasound & 15 & ANWU & $5.290 \pm 0.480$ & $0.156 \pm 0.014$ \\
Ascophyllum nodosum & $0.1 \mathrm{M} \mathrm{HCl}$ & Ultrasound & 15 & ANAU & $5.822 \pm 0.343$ & $0.128 \pm 0.008$ \\
Ascophyllum nodosum & Water & Solid liquid & 150 & ANWS & $4.599 \pm 0.030$ & $0.166 \pm 0.015$ \\
Ascophyllum nodosum & $0.1 \mathrm{M} \mathrm{HCl}$ & Solid liquid & 150 & ANAS & $4.304 \pm 0.165$ & $0.110 \pm 0.007$ \\
\hline
\end{tabular}

The highest laminarin content was measured in the extract of L. hyperborea and A. nodosum obtained using ultrasound and $0.1 \mathrm{M} \mathrm{HCl}$. In previous studies, $0.1 \mathrm{M} \mathrm{HCl}$ was also found to give higher extraction yields compared to water [14]. Moreover $\mathrm{HCl}$ at higher temperatures is more effective than at room temperature for laminarin extraction [7]. Laminarin content varies with species, with L. hyperborea having a higher level of laminarin compared to A. nodosum. Laminarin content also varies with factors such as harvesting season and geographical location. Laminarin is absent during the period of fast growth in spring, but in autumn and winter, it may represent up to $35 \%$ of the dried weight of the fronds [15]. Ultrasound was found to give higher extraction yields of laminarin. High power ultrasound treatment for 15 min achieved a higher extraction yield than conventional solid and liquid extraction for both seaweeds investigated. Laminarin yield for L. hyperborea extracted using ultrasound was $36.97 \%$ and $91.76 \%$ higher using water and $0.1 \mathrm{M} \mathrm{HCl}$ solvents respectively, whereas for A. nodosum laminarin yield was $15.02 \%$ and $35.62 \%$ higher using water and $0.1 \mathrm{M} \mathrm{HCl}$ solvents respectively. This can be attributed to the bubble cavitation phenomena generated by ultrasound waves. The implosion of cavitation bubbles generates macroturbulence, high-velocity interparticle collisions, and perturbations in microporous particles of the biomass. Cavitation near liquid-solid interfaces directs a fast-moving stream of liquid through the cavity at the surface. Impingement by these microjets results in surface peeling, erosion, and particle breakdown, facilitating the release of bioactive compounds and other components from the biological matrix. These effects increase the efficiency of extraction by increasing mass transfer by eddy and internal diffusion mechanisms [16]. Ultrasound assisted extraction (UAE) has also been successfully used for extraction of $A$. nodosum bioactive compounds including phenolic compounds, fucose and uronic acids $[17,18]$. The phenolic content was higher in L. hyperborea extracts. Water was demonstrated to be a better solvent than $\mathrm{HCl}$ for extraction of phenolics. This may be attributed to fact that acid solvents at a temperature of $70{ }^{\circ} \mathrm{C}$ may be detrimental to phenolic compounds leading to a lower content 
in acid extracts. The highest content of phenolics observed in L. hyperborea and A. nodosum was $0.365 \mathrm{mg}$ PGE/gdb and $0.166 \mathrm{mg} \mathrm{PGE} / \mathrm{g}_{\mathrm{db}}$, respectively.

\subsection{Characterization of Extracts}

Laminarin rich extracts were analyzed for their molecular weight distribution using Matrix Assisted Laser Desorption Ionization Quadrupole Time-of-Flight Mass Spectrometry (MALDI-Q-TOF-MS). Figure 1A,B show the mass spectra obtained in negative ion mode for a laminarin standard and an ultrasound assisted extract of L. hyperborea, respectively.
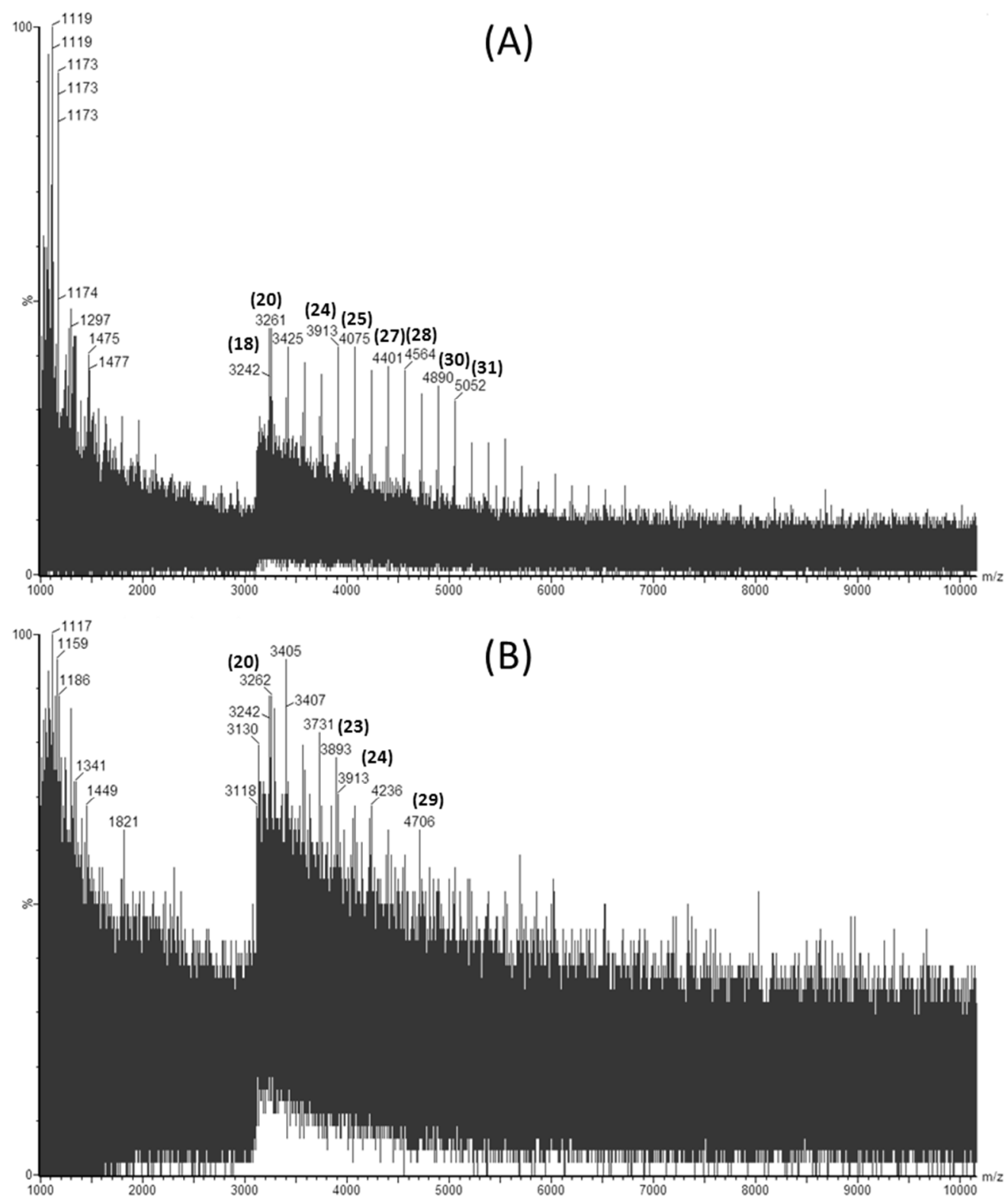

Figure 1. Matrix Assisted Laser Desorption Ionization Quadrupole Time-of-Flight Mass Spectrometry (MALDI-Q-TOF-MS) spectra showing the distribution of molecular weights of (A) commercial laminarin in sinapinic acid and (B) Laminaria hyperborea extract obtained by ultrasound assisted extraction using $0.1 \mathrm{M} \mathrm{HCl}$ as a solvent. 
The degree of polymerization (DP) for each laminarin peak is shown in bracketed bold numbers above the corresponding $\mathrm{m} / \mathrm{z}$ peaks. Four extracts were evaluated to investigate the effect of ultrasound and seaweed species on extraction of laminarin. Since M-chains and G-chains in the native laminarins differ by only 2 mass units, they cannot be distinguished from high molecular weight profiles [11]. Laminarin extracted using UAE from $L$. hyperborea had higher molecular weight laminarins ranging from 3242 to $5052 \mathrm{Da}$ (corresponding to DP20 to DP31) compared to the other extracts measured. Meanwhile, L. hyperborea obtained with conventional extraction yielded laminarins from DP20 to DP24 only. This demonstrates that ultrasound assisted extraction is more efficient than solid liquid extraction for extracting higher molecular weight laminarins. This can be attributed to the bubble cavitation phenomena releasing high molecular weight laminarins from L. hyperborea. Similar results were reported for extraction of high molecular weight phlorotannins from A. nodosum using ultrasound assisted extraction [18].

Ultrasound treated $A$. nodosum extracts yielded laminarins from DP25 to DP30 (molecular weights in the range of 4075 to $4884 \mathrm{Da}$ ). A. nodosum extracts did not yield lower molecular weight laminarins compared to L. hyperborea extracts. Moreover, L hyperborea extracts had a wide range of degree of polymerization compared to $A$. nodosum extracts.

\subsection{Bioactivities of Laminarin Rich Extract}

Laminarin has been found to possess various biological activities. The antioxidant and antimicrobial activities of the crude laminarin extract are shown in Table 2. The \% of 2,2-diphenyl-1-picrylhydrazyl (DPPH) inhibition of seaweed extracts was found to be highest in ultrasound treated extracts using acid solvent for L. hyperborea (87.58\%) and A. nodosum (93.24\%). O'Sullivan et al. [19] also found that A. nodosum was one of the most effective extracts for scavenging DPPH radicals. The extracts obtained with acid were found to have higher antioxidant activity than those obtained using water solvent. Further, authors reported that $A$. nodosum with $0.45 \mathrm{~g} / 100 \mathrm{~g}$ (Gallic acid equivalent) of phenolic content exhibited antioxidant activity of $25.6 \%$ DPPH inhibition [19]. Balboa et al. [20] have extensively reviewed antioxidant activities in brown seaweeds and they have reported that phenolic compounds possess antioxidant properties.

Table 2. Antioxidant activity as \%DPPH inhibition and antimicrobial activity as minimum inhibition concentration (MIC) of different extracts.

\begin{tabular}{cccccc}
\hline \multirow{2}{*}{ Sample } & $\begin{array}{c}\text { Antioxidant Activity } \\
\text { (\% DPPH Inhibition) }\end{array}$ & \multicolumn{4}{c}{ MIC (mg/mL) } \\
\cline { 3 - 6 } & 52.78 & 21.0 & 21.0 & 5.3 & 2.6 \\
\hline LHWU & 87.58 & 13.1 & 13.1 & 6.6 & 3.3 \\
LHAU & 73.91 & 45.6 & 22.8 & 11.4 & 5.7 \\
LHWS & 86.04 & 28.2 & 28.2 & 7.0 & 7.0 \\
LHAS & 61.46 & 43.2 & 21.6 & NI & NI \\
ANWU & 93.24 & 596.8 & 14.9 & 29.8 & 59.7 \\
ANAU & 15.13 & NI & 25.5 & NI & NI \\
ANWS & 87.82 & NI & 33.4 & 66.8 & 66.8 \\
ANAS & & & &
\end{tabular}


The extracts were tested for inhibition against two Gram positive (Staphylcoccus aureus and Listeria monocytogenes) and two Gram negative (Escherichia coli and Salmonella typhimurium) bacterial strains. All extracts of L. hyperborea were found to inhibit the growth of all the micro-organisms tested. The acid extracts had better inhibition of bacterial growth compared to water extracts. However, A. nodosum extracts only inhibited the growth of $S$. typhimurium completely. Only the acid extract of $A$. nodosum proved effective in inhibiting the bacterial growth of all species. The higher phenolic content and antioxidant activity of $L$. hyperborea extracts may enhance the antimicrobial efficacy of these extracts as many phenolic compounds have been shown to possess antimicrobial properties [21]. Laminarin rich extracts prepared using ultrasound and acid solvents had minimum inhibitory concentrations (MIC) of $13.1 \mathrm{mg} / \mathrm{mL}$ for E. coli and $S$. typhimurium and $6.6 \mathrm{mg} / \mathrm{mL}$ and $3.3 \mathrm{mg} / \mathrm{mL}$ for $S$. aureus and L. monocytogenes, respectively. This is the first reported study demonstrating that laminarin rich extracts possess microbial inhibitory activity. There are number of reports of seaweed extracts such as Sargassum polyophyllum, Sargassum flavellum, Padina australis and Sargassum binderi possessing antimicrobial activity [22]. However, ultrasound can be a novel alternative to high energy consuming traditional solid liquid extraction methods. These seaweed extracts have potential application in the preparation of antimicrobial products for example, a hydrogel wound dressing incorporating a seaweed Polysiphonia lanosa extract [23].

\section{Experimental Section}

\subsection{Chemicals and Reagents}

Laminarin produced from Laminaria digitata, 2,2-diphenyl-1-picrylhydrazyl (DPPH), phloroglucinol, sodium carbonate, Folin-Ciocalteu reagent (FCR), and hydrochloric acid (37\%) were obtained from Sigma-Aldrich (Wicklow, Ireland). GOPOD (glucose oxidase/peroxidase) reagent and $\beta$-glucosidase were obtained from Megazyme, Wicklow, Ireland.

\subsection{Seaweed Samples}

Brown seaweed A. nodosum and L. hyperborea were harvested from Finavarra, Co. Clare, Ireland in May 2014. Seaweed samples were washed thoroughly with fresh water to remove epiphytes and salt. Fresh seaweed samples were freeze dried. Dried seaweed was powdered using a hammer mill. Samples were stored at $4{ }^{\circ} \mathrm{C}$ prior to extraction studies.

\subsection{Ultrasound Assisted Extraction}

Ten grams of $A$. nodosum and $L$. hyperborea powders were extracted using $200 \mathrm{~mL}$ of solvent (distilled water or $0.03 \mathrm{M} \mathrm{HCl}$ ). $\mathrm{HCl}$ was used as the solvent for extraction based on preliminary studies and previously reported studies for the extraction of laminarin [24-26]. A $750 \mathrm{~W}$ ultrasonic processor (VC 750, Sonics and Materials Inc., Newtown, CT, USA) with a $13 \mathrm{~mm}$ diameter probe and constant frequency of $20 \mathrm{kHz}$ was used. Ultrasonic energy was controlled by setting the amplitude of the sonicator probe. Ultrasound treatment was applied for $15 \mathrm{~min}$ at an amplitude level of $60 \%$ which corresponds to an ultrasonic intensity of $35.61 \mathrm{~W} \mathrm{~cm}^{-2}$. Ultrasonic power dissipated was calculated at each amplitude level, with temperature $(T)$ recorded as a function of time $(t)$ under adiabatic conditions using a T-type 
thermocouple. From temperature versus time data, the initial temperature rise $d T / d t$ was determined by polynomial curve fitting. The ultrasonic power $(P)$ was determined using Equation (1) where $d T / d t$ is the change in temperature over time $\left({ }^{\circ} \mathrm{C} \mathrm{s}^{-1}\right), C_{p}$ is the specific heat of water $\left(4.18 \mathrm{~kJ} \mathrm{~kg}^{-1}{ }^{\circ} \mathrm{C}^{-1}\right)$, and $m$ is the mass $(\mathrm{kg})$.

$$
P=m C_{p}(d T / d t)_{t=0}
$$

Ultrasonic intensity $\left(\mathrm{W} \mathrm{cm}^{-2}\right)$ dissipated from an ultrasonic probe tip with diameter $D(\mathrm{~cm})$ is given by Equation (2)

$$
U I=\frac{4 P}{\pi D^{2}}
$$

The traditional solid-liquid method of extraction involved stirring at $70{ }^{\circ} \mathrm{C}$ for $2.5 \mathrm{~h}$ using distilled water and $0.1 \mathrm{M} \mathrm{HCl}$ as solvents and no ultrasound pretreatment was employed. The extracted samples were then centrifuged at $9000 \mathrm{rpm}$ for $30 \mathrm{~min}$. The supernatant was separated and precipitated with ethanol overnight at $4{ }^{\circ} \mathrm{C}$. The precipitated extract was freeze dried and stored at $-20{ }^{\circ} \mathrm{C}$ for further analysis. The different methods of extraction carried out in this experiment are listed in Table 3. The extraction yield (\%) was calculated by measuring the mass of freeze dried extract over the initial mass of the sample.

Table 3. Different methods of extraction and corresponding sample codes.

\begin{tabular}{ccccc}
\hline Seaweed Species & Solvent Type & Extraction & Time (min) & Sample Code \\
\hline Laminaria hyperborea & Water & Ultrasound & 15 & LHWU \\
Laminaria hyperborea & $0.1 \mathrm{M} \mathrm{HCl}$ & Ultrasound & 15 & LHAU \\
Laminaria hyperborea & Water & Solid liquid & 150 & LHWS \\
Laminaria hyperborea & $0.1 \mathrm{M} \mathrm{HCl}$ & Solid liquid & 150 & LHAS \\
Ascophyllum nodosum & Water & Ultrasound & 15 & ANWU \\
Ascophyllum nodosum & $0.1 \mathrm{M} \mathrm{HCl}$ & Ultrasound & 15 & ANAU \\
Ascophyllum nodosum & Water & Solid liquid & 150 & ANWS \\
Ascophyllum nodosum & $0.1 \mathrm{M} \mathrm{HCl}$ & Solid liquid & 150 & ANAS \\
\hline
\end{tabular}

\subsection{Laminarin Assay}

Laminarin in the extract was quantified by measuring the glucose concentration released by the enzymatic hydrolysis of laminarin [27]. A $100 \mu \mathrm{L}$ sample volume was incubated in $100 \mu \mathrm{L}$ of $\beta$-glucosidase enzyme at $40^{\circ} \mathrm{C}$ for $15 \mathrm{~min}$. After incubation, $3 \mathrm{~mL}$ of GOPOD (glucose oxidase/peroxidase) reagent was added. This mixture was incubated at $40{ }^{\circ} \mathrm{C}$ for $20 \mathrm{~min}$. Finally the absorbance of the sample was measured at $510 \mathrm{~nm}$ by UV-VIS spectrophotometer (UV3100PC, VWR International). Laminarin produced from Laminaria digitata was used as a standard.

\subsection{Total Phenolic Content}

Total phenolic content was determined using the method of Wang et al. [28]. Folin-Ciocalteau reagent was diluted with distilled water at a ratio of $1: 10$. An extract of $100 \mu \mathrm{L}$ was mixed with $100 \mu \mathrm{L}$ of diluted Folin-Ciocalteau reagent and $100 \mu \mathrm{L}$ of sodium bicarbonate $(20 \%, \mathrm{w} / \mathrm{v})$ was added to the mixture and diluted to $1000 \mu \mathrm{L}$ with distilled water. This solution was maintained at room temperature for $30 \mathrm{~min}$ 
and the absorbance was measured at $735 \mathrm{~nm}$ by UV-VIS spectrophotometer (UV3100PC, VWR International). Results were expressed as mg phloroglucinol equivalents (PGE)/gdb.

\subsection{Matrix Assisted Laser Desorption Ionization Quadrupole Time-of-Flight Mass Spectrometry (MALDI-Q-TOF-MS)}

Mass spectrometry of samples was performed using MALDI-Q-TOF-MS Waters Corporation, Milford, MA, USA). Prior to analysis, samples were dialyzed (molecular weight cut off of $10 \mathrm{kDa}$ ) in distilled water overnight. Aliquots of $5 \mu \mathrm{L}$ of sample were mixed with $5 \mu \mathrm{L}$ of matrix sinapinic acid. Finally $1-2 \mu \mathrm{L}$ of sample was plated on a 96 well stainless steel MALDI plate. Samples were allowed to dry and co-crystallize with the matrix at room temperature and the plate was loaded in MALDI-Q-TOF mass spectrometer. Mass spectral data were obtained in the negative-ion mode for a mass range of $\mathrm{m} / \mathrm{z} 1000$ to $\mathrm{m} / \mathrm{z} 10,000$.

\subsection{Antioxidant Activity-DPPH Method}

DPPH free radical scavenging inhibition assay was used to determine the antioxidant capacity of extracted samples [29]. Extract sample of $200 \mu \mathrm{L}$ was added to $800 \mu \mathrm{L}$ of $60 \mu \mathrm{M}$ DPPH in ethanol, decrease in absorbance was monitored at $517 \mathrm{~nm}$ by UV-VIS spectrophotometer (UV3100PC, VWR International) after $30 \mathrm{~min}$ incubation in dark. The readings were compared with the controls, which contained $200 \mu \mathrm{L}$ of water instead of the seaweed extract. The percent inhibition was calculated as

$$
\% \text { Inhibition }=\frac{\mathrm{Abs}_{\text {control }}-\mathrm{Abs}_{\text {sample }}}{\mathrm{Abs}_{\text {control }}} \times 100
$$

\subsection{Antimicrobial Activity—Iodonitrotetrazolium Chloride (INT) Dye Method}

\subsubsection{Bacterial Strains and Culture Conditions}

Seaweed extracts were tested for antimicrobial activity against the following strains of bacteria: Staphylcoccus aureus NCTC 8178, Escherichia coli DSM 1103, Listeria monocytogenes NCTC 11994 and Salmonella typhimurium SARB 65 . The strains were stored on ceramic beads in glycerol at $-80{ }^{\circ} \mathrm{C}$ prior to use. A bead of each strain was streaked on a nutrient agar plate and incubated for $18 \mathrm{~h}$ at $37^{\circ} \mathrm{C}$. A single colony was removed from each plate and inoculated into tubes containing $25 \mathrm{~mL}$ of sterile Mueller-Hinton Broth (MHB) and incubated for $22 \mathrm{~h}$ at $37^{\circ} \mathrm{C}$. Overnight cultures were vortexed and aliquots diluted appropriately in sterile MHB to produce solutions containing $\log _{10} 6.0 \pm 0.5 \mathrm{cells} / \mathrm{mL}$. Cell numbers were confirmed by plate counting. Antibiotic Gentamicin $(0.2 \mathrm{mg} / \mathrm{mL})$ was used as standard for negative growth.

\subsubsection{Minimum Inhibitory Concentration (MIC) Assay}

The MIC of each seaweed extract was carried out using a previously described microtitre method of Kenny, Smyth, Walsh, Kelleher, Hewage and Brunton [21]. Each extract (2 mg/mL) was prepared by dissolving the material in distilled water added to the first well of the plate followed by a serial dilution 
across the plate. Iodonitrotetrazolium chloride (INT) dye was used identify microbial growth [30]. The MIC of each extract against a bacterial strain was determined as the lowest sample concentration at which no pink color appeared. This process was repeated in triplicate for each bacterial strain to ensure reproducibility.

\section{Conclusions}

In this study, water and acid extracts from L. hyperborea and A. nodosum were obtained using ultrasound assisted extraction and solid liquid extraction. The extracts were purified to obtain laminarin rich extracts. The L. hyperborea extracts contained higher contents of laminarin. The overall laminarin content in all the extracts was low which may be attributed to seasonal and geographical factors. Ultrasound was demonstrated to be a more efficient method of extraction than solid liquid extraction based on laminarin content and molecular weight distribution observed in the extracts. The laminarin rich extracts were also studied for biological activities including anti-oxidant and anti-microbial activity. This study is the first report of laminarin rich extracts possessing anti-microbial activity. The use of laminarin as a nutraceutical ingredient should be further investigated due to its dietary fiber properties in addition to the anti-oxidant and anti-microbial activities reported in this paper.

\section{Acknowledgments}

The authors are thankful to Irish Research Council's Embark Initiative for financial support for this work. This work has also been supported by the Marine Functional Foods Research Initiative (NutraMara project) which is a programme for marine based functional food development. This project (Grant-Aid Agreement No. MFFRI/07/01) is carried out under the Sea Change Strategy with the support of the Marine Institute and the Department of Agriculture, Food and the Marine, funded under the National Development Plan 2007-2013.

\section{Author Contributions}

All authors contributed equally to the manuscript preparation. All authors approved the final version of the manuscript.

\section{Conflicts of Interest}

The authors declare no conflict of interest.

\section{References}

1. Kadam, S.U.; Prabhasankar, P. Marine foods as functional ingredients in bakery and pasta products. Food Res. Int. 2010, 43, 1975-1980.

2. Gupta, S.; Abu-Ghannam, N. Bioactive potential and possible health effects of edible brown seaweeds. Trends Food Sci. Technol. 2011, 22, 315-326.

3. Gupta, S.; Abu-Ghannam, N. Recent developments in the application of seaweeds or seaweed extracts as a means for enhancing the safety and quality attributes of foods. Innov. Food Sci. Emerg. Technol. 2011, 12, 600-609. 
4. Jiang, Z.; Okimura, T.; Yokose, T.; Yamasaki, Y.; Yamaguchi, K.; Oda, T. Effects of sulfated fucan, ascophyllan, from the brown Alga Ascophyllum nodosum on various cell lines: A comparative study on ascophyllan and fucoidan. J. Biosci. Bioeng. 2010, 110, 113-117.

5. Werner, A.; Kraan, S. Review of the Potential Mechanisation of Kelp Harvesting in Ireland; National University of Ireland: Galway, Ireland, 2004.

6. Rioux, L.E.; Turgeon, S.L.; Beaulieu, M. Characterization of polysaccharides extracted from brown seaweeds. Carbohydr. Polym. 2007, 69, 530-537.

7. Kadam, S.U.; Tiwari, B.K.; O'Donnell, C.P. Extraction, structure and biofunctional activities of laminarin from brown algae. Int. J. Food Sci. Technol. 2014, 50, 24-31.

8. Miao, H.-Q.; Ishai-Michaeli, R.; Peretz, T.; Vlodavsky, I. Laminarin sulfate mimics the effects of heparin on smooth muscle cell proliferation and basic fibroblast growth factor-receptor binding and mitogenic activity. J. Cell. Physiol. 1995, 164, 482-490.

9. Yvin, J.C.; LeVasseur, F.; Hud'Homme, F. Use of Laminarin and Oligosaccharides Derived Therefrom in Cosmetics and for Preparing a Skin Treatment Drug. U.S. Patent US5980916 A, 9 November 1999.

10. Zha, X.-Q.; Xiao, J.-J.; Zhang, H.-N.; Wang, J.-H.; Pan, L.-H.; Yang, X.-F.; Luo, J.-P. Polysaccharides in Laminaria japonica (LP): Extraction, physicochemical properties and their hypolipidemic activities in diet-induced mouse model of atherosclerosis. Food Chem. 2012, 134, 244-252.

11. Chizhov, A.O.; Dell, A.; Morris, H.R.; Reason, A.J.; Haslam, S.M.; McDowell, R.A.; Chizhov, O.S.; Usov, A.I. Structural analysis of laminarans by MALDI and FAB mass spectrometry. Carbohydr. Res. 1998, 310, 203-210.

12. Date, Y.; Sakata, K.; Kikuchi, J. Chemical profiling of complex biochemical mixtures from various seaweeds. Polym. J. 2012, 44, 888-894.

13. Vilkhu, K.; Mawson, R.; Simons, L.; Bates, D. Applications and opportunities for ultrasound assisted extraction in the food industry-A review. Innov. Food Sci. Emerg. Technol. 2008, 9, 161-169.

14. Deville, C.; Damas, J.; Forget, P.; Dandrifosse, G.; Peulen, O. Laminarin in the dietary fibre concept. J. Sci. Food Agric. 2004, 84, 1030-1038.

15. Rinaudo, M. Seaweed polysaccharides. In Comprehensive Glycoscience; Johannis, P.K., Ed.; Elsevier: Oxford, UK, 2007; pp. 691-735.

16. Kadam, S.U.; Tiwari, B.K.; O’Donnell, C.P. Application of novel extraction technologies for bioactives from marine algae. J. Agric. Food Chem. 2013, 61, 4667-4675.

17. Kadam, S.U.; Tiwari, B.K.; O’Connell, S.; O’Donnell, C.P. Effect of ultrasound pre-treatment on the extraction kinetics of bioactives from brown seaweed (Ascophyllum nodosum). Sep. Sci. Technol. 2014, 50, 1-6.

18. Kadam, S.U.; Tiwari, B.K.; Smyth, T.J.; O’Donnell, C.P. Optimization of ultrasound assisted extraction of bioactive components from brown seaweed Ascophyllum nodosum using response surface methodology. Ultrason. Sonochem. 2015, 23, 308-316.

19. O’Sullivan, A.M.; O’Callaghan, Y.C.; O’Grady, M.N.; Queguineur, B.; Hanniffy, D.; Troy, D.J.; Kerry, J.P.; O'Brien, N.M. In vitro and cellular antioxidant activities of seaweed extracts prepared from five brown seaweeds harvested in spring from the west coast of Ireland. Food Chem. 2011, 126, 1064-1070. 
20. Balboa, E.M.; Conde, E.; Moure, A.; Falqué, E.; Domínguez, H. In vitro antioxidant properties of crude extracts and compounds from brown algae. Food Chem. 2013, 138, 1764-1785.

21. Kenny, O.; Smyth, T.J.; Walsh, D.; Kelleher, C.T.; Hewage, C.M.; Brunton, N.P. Investigating the potential of under-utilised plants from the Asteraceae family as a source of natural antimicrobial and antioxidant extracts. Food Chem. 2014, 161, 79-86.

22. Jaswir, I.; Tawakalit Tope, A.-H.; Raus, R.A.; Ademola Monsur, H.; Ramli, N. Study on anti-bacterial potentials of some Malaysian brown seaweeds. Food Hydrocoll. 2014, 42, 275-279.

23. Tan, S.P.; McLoughlin, P.; O’Sullivan, L.; Prieto, M.L.; Gardiner, G.E.; Lawlor, P.G.; Hughes, H. Development of a novel antimicrobial seaweed extract-based hydrogel wound dressing. Int. J. Pharm. 2013, 456, 10-20.

24. Black, W.A.P.; Cornhill, W.J.; Dewar, E.J.; Woodward, F.N. Manufacture of algal chemicals. III. Laboratory-scale isolation of laminarin from brown marine algae. J. Appl. Chem. 1951, 1, 505-517.

25. Ermakova, S.; Men'shova, R.; Vishchuk, O.; Kim, S.-M.; Um, B.-H.; Isakov, V.; Zvyagintseva, T. Water-soluble polysaccharides from the brown alga Eisenia bicyclis: Structural characteristics and antitumor activity. Algal Res. 2013, 2, 51-58.

26. Jin, W.; Zhang, W.; Wang, J.; Ren, S.; Song, N.; Duan, D.; Zhang, Q. Characterization of laminaran and a highly sulfated polysaccharide from Sargassum fusiforme. Carbohydr. Res. 2014, 385, 58-64.

27. Devillé, C.; Gharbi, M.; Dandrifosse, G.; Peulen, O. Study on the effects of laminarin, a polysaccharide from seaweed, on gut characteristics. J. Sci. Food Agric. 2007, 87, 1717-1725.

28. Wang, X.; Wu, Y.; Chen, G.; Yue, W.; Liang, Q.; Wu, Q. Optimisation of ultrasound assisted extraction of phenolic compounds from Sparganii rhizoma with response surface methodology. Ultrason. Sonochemistry 2013, 20, 846-854.

29. Shetty, K.; Curtis, O.F.; Levin, R.E.; Witkowsky, R.; Ang, W. Prevention of vitrification associated with in vitro shoot culture of oregano (Origanum vulgare) by Pseudomonas spp. J. Plant Physiol. 1995, 147, 447-451.

30. Eloff, J.N. A sensitive and quick microplate method to determine the minimal inhibitory concentration of plant extracts for bacteria. Planta Med. 1998, 64, 711-713.

(C) 2015 by the authors; licensee MDPI, Basel, Switzerland. This article is an open access article distributed under the terms and conditions of the Creative Commons Attribution license (http://creativecommons.org/licenses/by/4.0/). 